\title{
Transiorming a Targeted Porphyrin Theranostic Agent into a PET Imaging Probe for Cancer
}

\author{
Jiyun Shi1,2,3 ${ }^{*}$, Tracy W.B. Liu ${ }^{1,2}{ }^{*}$, Juan Chen², David Green², David Jaffray ${ }^{1,2}$, Brian C. Wilson ${ }^{1,2}$, Fan Wang ${ }^{3}$ \\ and Gang Zheng1,2 $\bowtie$
}

1. Department of Medical Biophysics, University of Toronto, Toronto, Canada;

2. Ontario Cancer Institute, University Health Network, Toronto, Canada;

3. Medical Isotopes Research Center, Peking University, Beijing, China.

* J. Shi and T. Liu contributed equally to this work.

$\triangle$ Corresponding author: Gang Zheng, PhD, University of Toronto, 101 College Street, TMDT 5-363, Toronto, ON M5G1L7, Canada. Tel: 416-581-7666; Fax: 416-581-7667; E-mail: gang.zheng@uhnres.utoronto.ca

(C) Ivyspring International Publisher. This is an open-access article distributed under the terms of the Creative Commons License (http:/ / creativecommons.org/ licenses/by-nc-nd/3.0/). Reproduction is permitted for personal, noncommercial use, provided that the article is in whole, unmodified, and properly cited.

Received: 2011.07.27; Accepted: 2011.08.27; Published: 2011.09.15

\begin{abstract}
Porphyrin based photosensitizers are useful agents for photodynamic therapy (PDT) and fluorescence imaging of cancer. Porphyrins are also excellent metal chelators forming highly stable metallo-complexes making them efficient delivery vehicles for radioisotopes. Here we investigated the possibility of incorporating ${ }^{64} \mathrm{Cu}$ into a porphyrin-peptide-folate (PPF) probe developed previously as folate receptor (FR) targeted fluorescent/PDT agent, and evaluated the potential of turning the resulting ${ }^{64} \mathrm{Cu}$-PPF into a positron emission tomography (PET) probe for cancer imaging. Noninvasive PET imaging followed by radioassay evaluated the tumor accumulation, pharmacokinetics and biodistribution of ${ }^{64} \mathrm{Cu}-\mathrm{PPF} .{ }^{64} \mathrm{Cu}-\mathrm{PPF}$ uptake in FR-positive tumors was visible on small-animal PET images with high tumor-to-muscle ratio $(8.88 \pm 3.60)$ observed after $24 \mathrm{~h}$. Competitive blocking studies confirmed the FR-mediated tracer uptake by the tumor. The ease of efficient ${ }^{64} \mathrm{Cu}$-radiolabeling of PPF while retaining its favorable biodistribution, pharmacokinetics and selective tumor uptake, provides a robust strategy to transform tumor-targeted porphyrin-based photosensitizers into PET imaging probes.
\end{abstract}

Key words: Copper-64, Porphyrin, PET, Folate receptor, Peptides

\section{Introduction}

Porphyrins represent one of the oldest, most widely studied chemical structures, both in nature and in biomedical applications [1-2]. Due to their favorable photophysical properties, such as long wavelength absorption and emission, easy derivatization, high singlet oxygen quantum yield and low in vivo toxicity, porphyrins have found particular success for photodynamic therapy (PDT) and fluorescence imaging of cancer [3-6]. Several thorough reviews dis- cussing the advantages of porphyrins as photosensitizers in photodynamic therapy may be found elsewhere $[3,5,7]$. Additionally, porphyrins are excellent metal chelators, forming highly stable metallo-complexes [8]. With the well-established stable chelation of $\mathrm{Cu}^{2+}$ to porphyrins, the potential use of ${ }^{64} \mathrm{Cu}$-porphyrin for the detection of cancer in patients was recognized well over half a century ago [9]. The radioactive ${ }^{64} \mathrm{Cu}$-porphyrin is extremely stable to 
demetallation and was first used in vivo in 1951 to develop coincident scintillation counters permitting more accurate localization of radioisotopes [10]. Despite the emerging recognition of ${ }^{64} \mathrm{Cu}$ as a suitable radionuclide $\left(\mathrm{t}_{1 / 2}=12.7 \mathrm{~h}, \beta^{+}: 17.4 \%, \mathrm{E}_{\beta+\max }=656 \mathrm{keV}\right.$; $\left.\beta=39 \%, \mathrm{E}_{\beta-\max }=573 \mathrm{keV}\right)$ in positron emitting tomography (PET) imaging [11-12], there have been few efforts and even less promising results to date for using ${ }^{64} \mathrm{Cu}$-labeled porphyrins as PET probes [13-15]. In large part this is due to their poor tumor targeting, as well as the technical limitations of earlier PET scanners. The field went into hiatus until the 1980s when Wilson et al. attempted to detect brain tumors using ${ }^{64} \mathrm{Cu}$-porphyrin with the emerging technology of PET. This effort failed to generate wide interest, due to the limited tumor localization of the particular ${ }^{64} \mathrm{Cu}$-porphyrin and the poor spatial resolution (8 $\mathrm{mm}$ ) of PET scanners at that time [13-14]. However, a critical result from this study was that ${ }^{64} \mathrm{Cu}$-labeling did not alter the main characteristics (biodistribution, pharmacokinetics, clearance) of the host porphyrin molecules [13]. Although there were sporadic efforts subsequently [15-16], the overall common understanding of ${ }^{64} \mathrm{Cu}$-porphyrins' relative inability to detect cancer remains unchallenged.

We have previously developed a folate receptor (FR)-targeted optical imaging and PDT agent, porphyrin-GDEVDGSGK-folate (PPF, Figure 1) [17]. PPF is composed of three modules: 1) pyropheophorbide- $\alpha$ (Pyro), a near-infrared fluorescent porphyrin, 2) folate for targeted delivery of Pyro to FR-expressing cancer cells, and 3) a short peptide as a pharmacokinetics modifying (PKM) linker. We have demonstrated, both in vitro and in vivo, that the use of three functional modules significantly improved tumor uptake efficiency, pharmacokinetics and biodistribution of the porphyrin moiety itself [17]. Here we hypothesize that incorporating ${ }^{64} \mathrm{Cu}$ into the Pyro moiety of PPF ( $\left.{ }^{64} \mathrm{Cu}-\mathrm{PPF}\right)$ will effectively switch PPF from a targeted fluorescent/PDT agent into a PET probe for cancer imaging. Porphyrins have several ideal characteristics as ${ }^{64} \mathrm{Cu}$ chelators: their aforementioned stable ${ }^{64} \mathrm{Cu}$-chelating ability [10] the clinically-validated minimal toxicity of ${ }^{64} \mathrm{Cu}$-prophyrin [9], the compatible half-lives of ${ }^{64} \mathrm{Cu}$ and the pharmacokinetics of porphyrin [13-14], and the fact that ${ }^{64} \mathrm{Cu}$-chelation does not alter the biodistribution of the host porphyrin $[13,18]$. We envision that these features of ${ }^{64} \mathrm{Cu}$-prophyrin, coupled with the promising tumor targeting ability of PPF (Supplementary Material: Figure S1) and the high resolution and deep tissue imaging capability of modern PET technology [19-21], will enable ${ }^{64} \mathrm{Cu}-\mathrm{PPF}$ to 1 ) become a novel cancer-targeted PET imaging probe, 2) facilitate the development of photosensitizers via quantitative biodistribution and pharmacokinetics assessment, 3) serve as a novel means to monitor porphyrin tumor uptake in patients receiving PDT, either by pre-treatment PET scanning or by administering a cocktail of labeled and unlabelled porphyrin and, most importantly 4) open the door to transform a variety of porphyrin photosensitizers into PET probes [22-23].

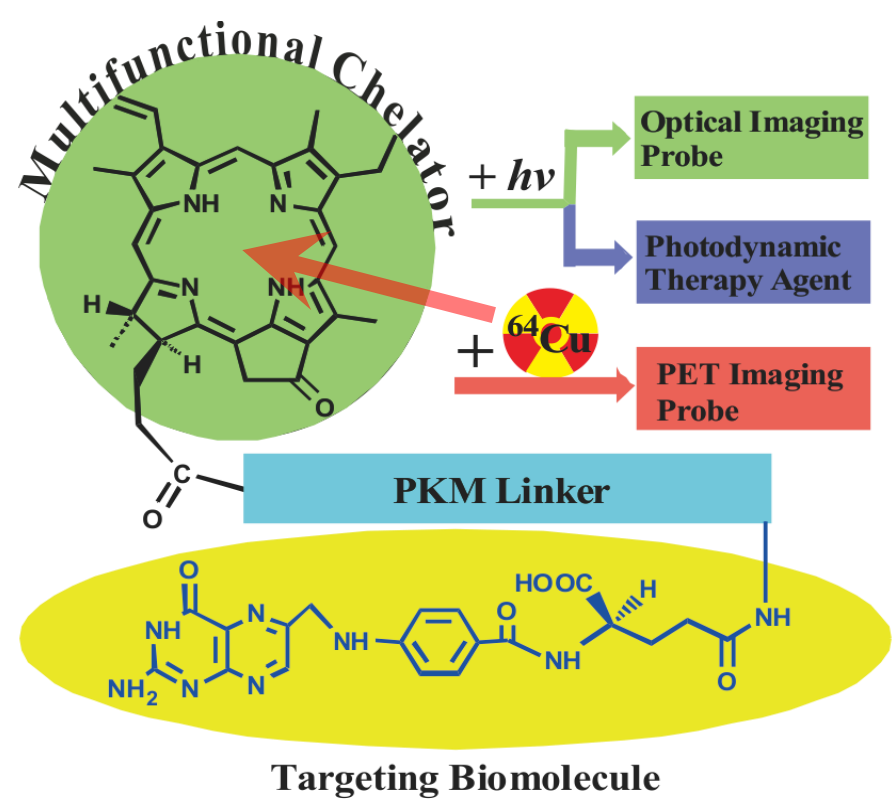

Figure I. The structure design of the PPF (Pyro-PKM Linker-Folate, molecular weight of $1800 \mathrm{~g} / \mathrm{mol})$. Here the PKM linker (pharmacokinetics modifying linker) is the peptide sequence, GDEVDGSGK.

\section{Experimental Section}

${ }^{64} \mathrm{Cu}$-Radiolabeling: In a $1.5 \mathrm{~mL}$ eppendorf tube, $2 \mu \mathrm{L}$ DMSO was added to dissolve $50 \mu \mathrm{g}(\sim 30 \mathrm{nmol})$ of PPF (Pyro-Peptide-Folate). $0.1 \mathrm{~mL}$ of $0.1 \mathrm{M} \mathrm{NH}_{4} \mathrm{OAc}$ buffer $(\mathrm{pH}=5.5)$ was added and vortexed, producing a dark green solution. $0.10 \mathrm{~mL}$ of ${ }^{64} \mathrm{Cu}$ (Acetate) ${ }_{2}$ solution $(0.5-5.0 \mathrm{mCi})$ was then added and the reaction mixture was heated in a water bath at $60{ }^{\circ} \mathrm{C}$ for 20 min. After cooling to room temperature, a sample of resulting solution was analyzed by radio-UPLC.

The radio-UPLC method: The radio-UPLC method used the Acquity ${ }^{\mathrm{TM}}$ Waters UPLC system (Waters Corp., Milford, MA) equipped with PDA detector and Bioscan radioactive detector and Acquity BEH C18 column $(2.1 \times 100 \mathrm{~mm}, 1.7 \mu \mathrm{m}$; Waters $)$. The flow rate was $0.8 \mathrm{~mL} / \mathrm{min}$. The mobile phase was isocratic with $80 \%$ solvent $\mathrm{A}(0.1 \mathrm{M}$ TEAA, $\mathrm{pH} 7)$ and 
$20 \%$ solvent B (acetonitrile) at $0 \mathrm{~min}$, followed by a gradient mobile phase shifting from $20 \%$ solvent $B$ at 0 min to $100 \%$ solvent B at $12 \mathrm{~min}$ and back to $20 \%$ solvent $B$ at $13-15$ min.

Purification: Purification with Sep-Pak C18 cartridge was done according to the following procedures: 1) Attach a syringe to the Sep-Pak C18 cartridge. 2) Flush the column with $5 \mathrm{~mL}$ of ethanol and flush the column with $10 \mathrm{~mL}$ of saline to equilibrate the column. 3) Load the sample onto the column and wash the sample with $10 \mathrm{~mL}$ of saline. 4) Elute with $400 \mu \mathrm{l}$ of $80 \%$ ethanol, collect the fractions of purified sample. 5) Dry samples using a speed-vacuum and resuspend in saline. A certain amount of radioactive is washed down in step 3 if unlabeled free ${ }^{64} \mathrm{Cu}$ is observed in the system. With the natural dark green color of Pyro, the elution of Pyro-conjugate can be easily and directly monitored visually in step 4, and the fractions with the deepest color contain the highest concentration of labeled and unlabeled Pyro-conjugate.

Dose Preparation: ${ }^{64} \mathrm{Cu}-\mathrm{PPF}$ was prepared and administered without any further purification. The dose solution was prepared by dissolving the radiotracer in saline to a concentration of $2.5-5.0 \mathrm{mCi} / \mathrm{mL}$ for MicroPET imaging, and diluted to a concentration of $0.1-0.5 \mathrm{mCi} / \mathrm{mL}$. The resulting solution was filtered with a $0.20 \mu$ Millex-LG filter before being administered to the animals. Each tumor-bearing mouse was injected via the tail vein with $0.1-0.2 \mathrm{~mL}$ of the filtered dose solution.

Solution Stability: For in vitro solution stability studies, ${ }^{64} \mathrm{Cu}-\mathrm{PPF}$ was prepared and used without any further purification. The ${ }^{64} \mathrm{Cu}-\mathrm{PPF}$ was dissolved in a saline or serum solution (10\% FBS in saline) with a final amount of $1 \mathrm{mCi} / \mathrm{mL}$ and left at room temperature for stability measurements. Samples of the resulting solution were analyzed by radio-UPLC at 0,6 , and $24 \mathrm{~h}$ post-incubation. The samples from the serum solution were centrifuged before UPLC injection.

In vivo xenograft model: All animal studies were carried out under institutional approval (University Health Network, Toronto, Canada). Adult athymic female nude mice were inoculated subcutaneously with $1 \times 10^{6}$ of KB (FR-positive human epidermal cancer) or MT-1 (FR-positive human breast carcinoma) cells in $200 \mu \mathrm{L}$ of media in the left flank under general anesthesia with $2 \%$ isoflurane in oxygen. Animals were maintained in pathogen-free conditions in autoclaved microisolator cages. After 2 weeks, the tumors were $5-10 \mathrm{~mm}$ in diameter.

MicroPET/CT Imaging. MicroPET imaging was performed using a MicroPET R4 rodent model scanner (Concorde Microsystems, Knoxville, TN). The tumor-bearing mice $(n=3)$ were anesthetized with $2 \%$ isoflurane in oxygen, and injected with $\sim 500 \mu \mathrm{Ci}$ of ${ }^{64} \mathrm{Cu}-\mathrm{PPF}$ via the tail vein, and placed near the center of the FOV where the highest resolution and sensitivity are obtained. A 10-min static PET image was obtained at $4 \mathrm{~h}$ post injection and 30-45 min static PET images were acquired at $24 \mathrm{~h}$ post injection. Throughout the imaging, mice were kept anesthetized and directly transferred to the scanner, together with the supporting bed, without any movement. CT scanning was carried out immediately after each PET imaging session. For the blocking experiment, a mouse bearing a KB xenograft was injected with 500 $\mu \mathrm{Ci}$ of ${ }^{64} \mathrm{Cu}$-PPF along with 500 -fold excess free folic acid. The static PET images were then acquired with same parameters at 4 and $24 \mathrm{~h}$ post injection.

Biodistribution Studies: Biodistribution studies were performed using the athymic nude mice bearing KB xenografts. Twenty tumor-bearing mice (25 - $30 \mathrm{~g})$ were randomly divided into 5 groups. The ${ }^{64} \mathrm{Cu}$ radiotracer $(\sim 12.5 \mu \mathrm{Ci}$ in $0.1 \mathrm{~mL}$ saline) was administered into each animal via the tail vein. Four animals were euthanized by with $2 \%$ isoflurane, exsanguinated, and opening of the thoracic cavity at 4 or $24 \mathrm{~h}$ post injection. Blood samples were withdrawn from the heart through a syringe. Organs were excised, washed with saline, dried with absorbent tissue, weighed and counted on a $\gamma$-counter (Perkin-Elmer Wizard-1480). Organs of interest included the tumor, heart, spleen, lungs, liver, kidneys, adrenal, stomach, intestine, muscle, bone and brain. Organ uptake was calculated as a percentage of the injected dose per gram of tissue (\% ID/g). For the blocking experiment, each animal was administered with $\sim 12.5 \mu \mathrm{Ci}$ of ${ }^{64} \mathrm{Cu}$ radiotracer along with more than 500 -fold excess folic acid, and animals were sacrificed at 4 or $24 \mathrm{~h}$ post injection for biodistribution studies. The organ uptake (\%ID/g) was compared to that obtained in the absence of excess folic acid at the same time point. The biodistribution data and target-to-background (T/B) ratios are reported as the mean and standard deviation based on results from three animals at each time point. Comparison between two different radiotracers was made using the two-way ANOVA test (GraphPad Prim 5.0, San Diego, CA). The level of significance was set at $p<0.05$.

Metabolism: Normal athymic nude mice $(n=2)$ were used to evaluate the metabolic stability of ${ }^{64} \mathrm{Cu}$-labeled PPF. Each mouse was injected with the ${ }^{64} \mathrm{Cu}$ radiotracer at a dose of $\sim 200 \mu \mathrm{Ci}$ in $0.1 \mathrm{~mL}$ of saline via the tail vein. Urine samples were collected at $1.0 \mathrm{~h}$ post injection by manual void and mixed with saline solution. The mixture was centrifuged at 8,000 rpm for $3 \mathrm{~min}$. The supernatant was collected and 
filtered through a $0.20 \mu \mathrm{m}$ Millex-LG filter unit. The filtrate was analyzed by radio-UPLC.

\section{Results}

An important condition for receptor-targeted delivery of radiolabeled agents is the development of labeling chemistry that allows for the stable and facile preparation of radiolabeled biologically-active molecules. The half-life of ${ }^{64} \mathrm{Cu}\left(\mathrm{t}_{1 / 2}=12.7 \mathrm{~h}\right)$ provides adequate time for radiolabeling chemistry and imaging over 24-48 $\mathrm{h}$ to accommodate PPF accumulation at targeted sites [17]. The PKM linker enhances the water solubility of PPF (Figure 1), thereby improving its cancer-specificity, since water-soluble porphyrins give assistance to increased affinity for tumor tissues [17-18]. PPF was easily dissolved in an aqueous solution with a small amount of DMSO $(\leq 1 \%)$ and was radiolabeled efficiently in $0.1 \mathrm{M}$ ammonium acetate buffer at $60^{\circ} \mathrm{C}$ for $10-20 \mathrm{~min}$ (Figure 2a). The success of the ${ }^{64} \mathrm{Cu}$ labeling was determined by radio-UPLC (Ultra Performance Liquid Chromatography) using a $\mathrm{C}_{18}$ column. Using simultaneous multichannel monitoring of the pyro-specific UV absorbance at $410 \mathrm{~nm}$ and a radioactive signal, the incorporation of ${ }^{64} \mathrm{Cu}$ into PPF was observed. As expected, no free ${ }^{64} \mathrm{Cu}$ was detected during the radiolabeling procedure, based on the radio-UPLC radioactive channel chromatography (Figure $2 \mathrm{~b}$ ). The radiolabeling yield was $>99.9 \%$ and the radiochemical purity of ${ }^{64} \mathrm{Cu}-\mathrm{PPF}$ was $>98 \%$ and the specific activity was $2.66 \times 10^{6} \mathrm{GBq} / \mathrm{mol}$. Milder temperatures (room temperature and $37^{\circ} \mathrm{C}$ ) were also evaluated but resulted in a lower radiolabeling efficiency $(50-80 \%)$, even after 20-30 min incubation. In this case, $\mathrm{C}_{18}$-cartridge purification removed all free ${ }^{64} \mathrm{Cu}$ (see details of method in Supporting Information) and PPF was efficiently radiolabeled with ${ }^{64} \mathrm{Cu}$, successfully transforming the optical theranostic into a nuclear medicine tracer.
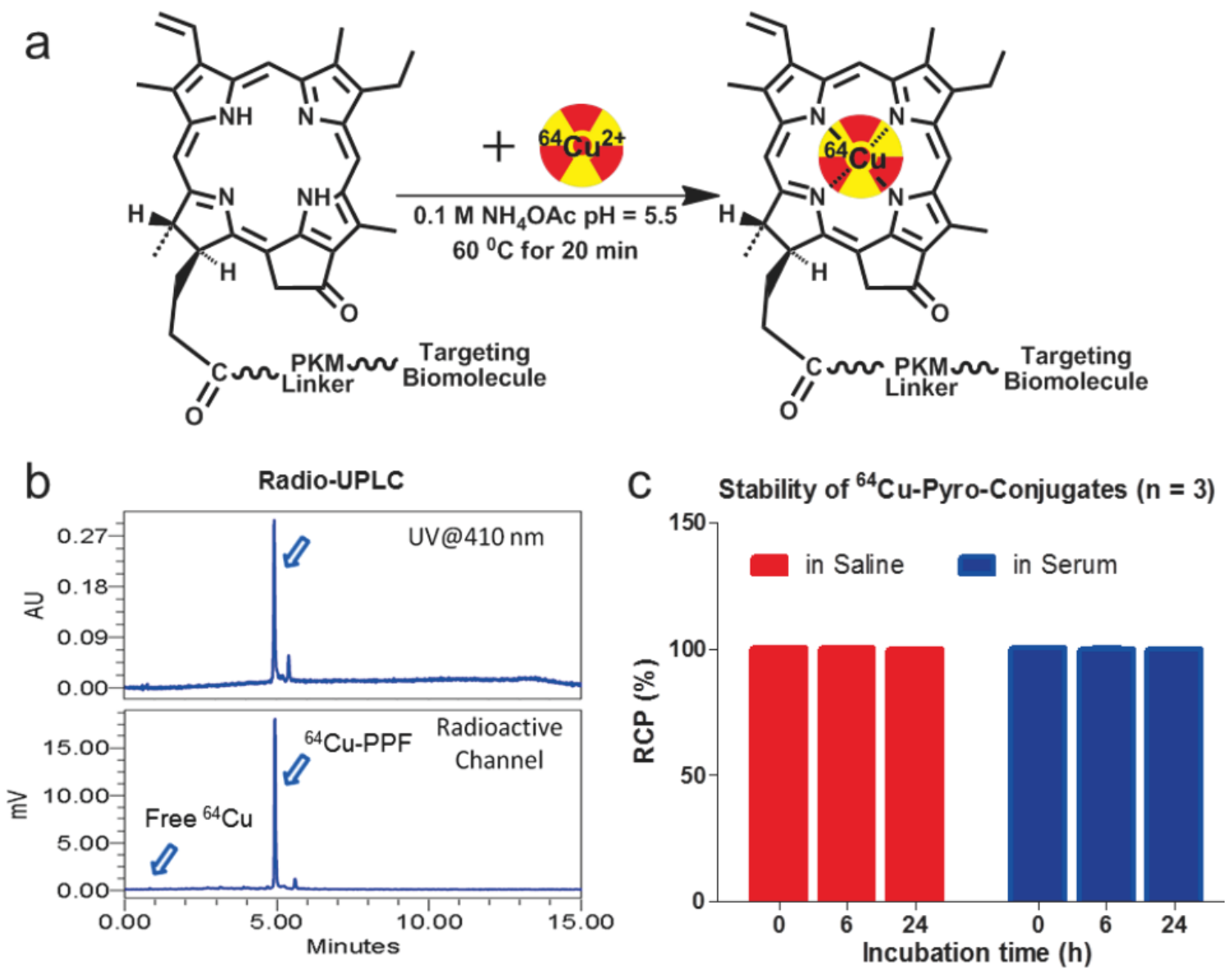

Figure 2. The radiolabeling procedure, quality control and stability of ${ }^{64} \mathrm{Cu}-\mathrm{PPF}$. a) The scheme of the ${ }^{64} \mathrm{Cu}$-radiolabeling of Pyro-Conjugates, b) quality control of ${ }^{64} \mathrm{Cu}$-labeled PPF by radio-UPLC, c) in vitro stability of ${ }^{64} \mathrm{Cu}$-Pyro-Conjugates in saline or serum (I0\% FBS) solution (RCP $=$ The radiochemical purity of ${ }^{64} \mathrm{Cu}$-Pyro-Conjugates) $(n=3)$. 
The stability of the radio-metalloporphyrin is critical to the design of a radiopharmaceutical. The ${ }^{64} \mathrm{Cu}-\mathrm{PPF}$ stability was separately measured in both a saline and serum solution (10\% FBS) for $24 \mathrm{~h}$ (Figure 3). These data demonstrates that the incorporation of ${ }^{64} \mathrm{Cu}$ into PPF resulted in a very stable metalloporphyrin complex. To evaluate the metabolic stability of the ${ }^{64} \mathrm{Cu}-\mathrm{PPF}$ in vivo, athymic nude mice weighing 25-30 g were administered $200 \mu \mathrm{Ci}(100 \mu \mathrm{L}){ }^{64} \mathrm{Cu}-\mathrm{PPF}$ intravenously (tail vein). All animal studies were carried out under institutional approval (Ontario Cancer Institute, Toronto, Canada, AUP 2273.0). Urine samples were collected at $1 \mathrm{~h}$ post injection. Samples was centrifuged, filtered, and evaluated by radio-UPLC. The UPLC chromatogram showed one intact ${ }^{64} \mathrm{Cu}-\mathrm{PPF}$ peak (Figure 4) indicating good metabolic stability. Only a few chelators have been reported to have both high stability and efficient radiolabeling protocols under mild conditions [24-26].

We next evaluated the potential of ${ }^{64} \mathrm{Cu}-\mathrm{PPF}$ for PET imaging of FR expression in tumors in vivo. The FR-positive KB xenograft mouse model previously used for PPF-based optical imaging and PDT was used [17]. Animals weighing 25-30 g received a 500 $\mu \mathrm{Ci}(\sim 18 \mathrm{MBq})$ intravenous injection of ${ }^{64} \mathrm{Cu}-\mathrm{PPF}$. $\mathrm{Cu}$ toxicity is not a concern as the dose used for PET studies $(500 \mu \mathrm{Ci}, \sim 18 \mathrm{MBq})$ is far lower than those used for radiotherapy studies in which a $10 \mathrm{mCi}(\sim 370$ $\mathrm{MBq})$ of ${ }^{64} \mathrm{Cu}$ has been administered in murine models with no overt toxicity reported [27-29]. MicroPET imaging and MicroCT scans were performed accordingly at 4 and $24 \mathrm{~h}$ post-injection. The favorable tumor-to-background ratio of ${ }^{64} \mathrm{Cu}-\mathrm{PPF}$ is evident in Figure 5a. ${ }^{64} \mathrm{Cu}-\mathrm{PPF}$ easily delineates the tumor from all other tissues by PET. Inhibition imaging studies were conducted by co-injection of the radiotracer with 500 -fold excess folic acid. Figure $3 \mathrm{~b}$ demonstrates that the uptake of ${ }^{64} \mathrm{Cu}-\mathrm{PPF}$ at the tumor site was significantly blocked by excess folic acid, indicating that ${ }^{64} \mathrm{Cu}-\mathrm{PPF}$ targeting is FR-mediated. Biodistribution studies of ${ }^{64} \mathrm{Cu}-\mathrm{PPF}$ in the $\mathrm{KB}$ xenograft models at 4 and $24 \mathrm{~h}$ post-injection were also performed. All vital organs (including heart, liver, spleen, kidney, lung, stomach, large-intestine, small intestine, adrenal, brain, muscle and bone) and tumors were removed, washed with normal saline and weighed for radioassay. The highest uptake was in the kidneys, corresponding to the PET imaging results. Tumor uptake was $3.02 \pm 0.55 \%$ injected dose (ID)/g at $4 \mathrm{~h}$ and 1.64 $\pm 0.33 \% \mathrm{ID} / \mathrm{g}$ at $24 \mathrm{~h}$ post injection (Figure $5 \mathrm{c}$ ).

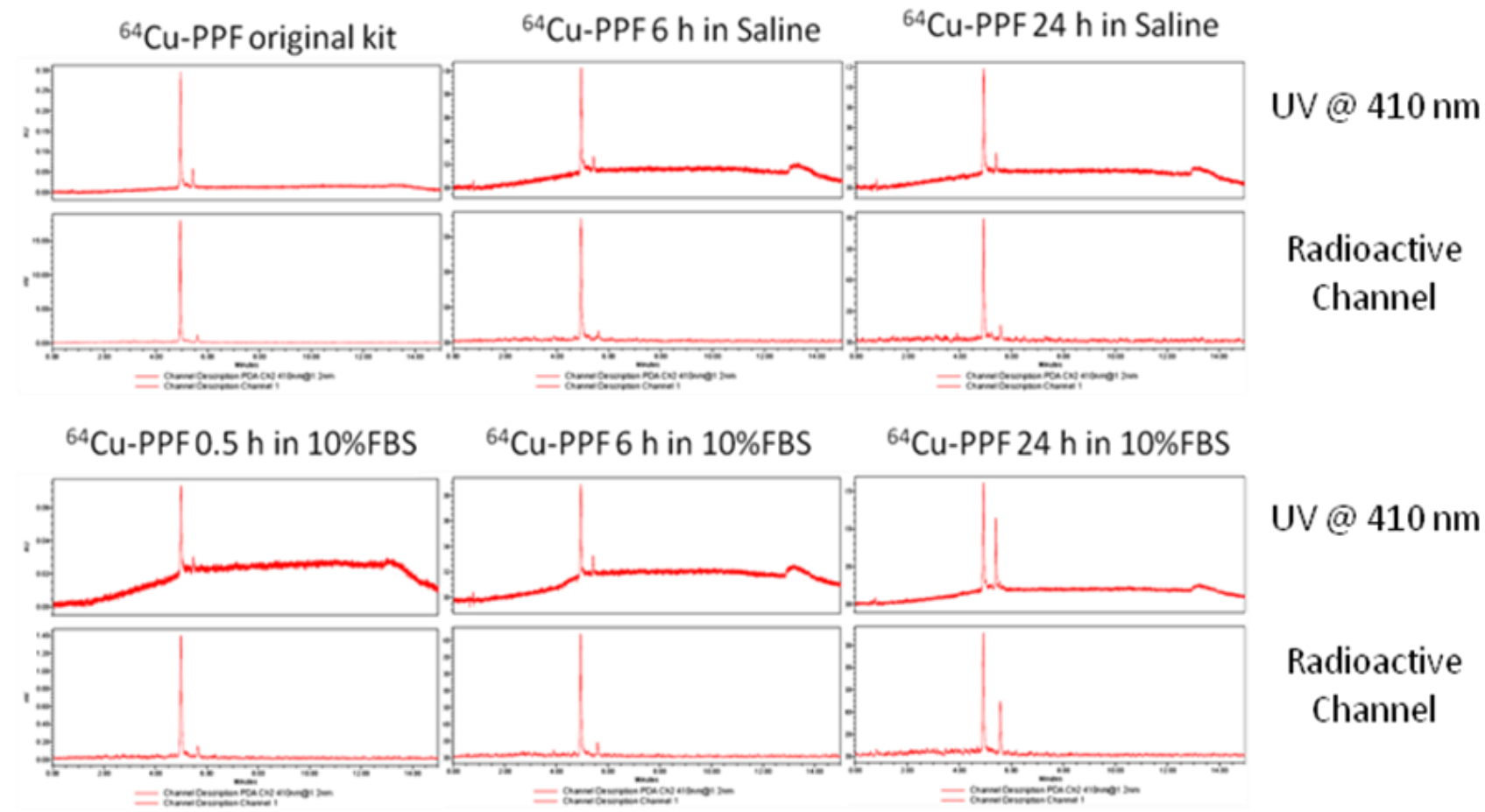

Figure 3. The in vitro stability of ${ }^{64} \mathrm{Cu}$-pyropheophorbide-a conjugates in saline (a) and serum (I0\% FBS) (b) was measured by radio-UPLC with UV $410 \mathrm{~nm}$ channel and radioactivity channel. We demonstrate the stability of ${ }^{64} \mathrm{Cu}$ chelation within the porphyrin, pyropheophorbide-a. Folic acid conjugation does not affect the stability of ${ }^{64} \mathrm{Cu}$ chelation as both ${ }^{64} \mathrm{Cu}-\mathrm{PPF}$ (major peak, with folate) and ${ }^{64} \mathrm{Cu}-\mathrm{PP}$ (minor peak, no folate) show that ${ }^{64} \mathrm{Cu}$ complexes stably to the porphyrin as no free ${ }^{64} \mathrm{Cu}$ is observed over time. 

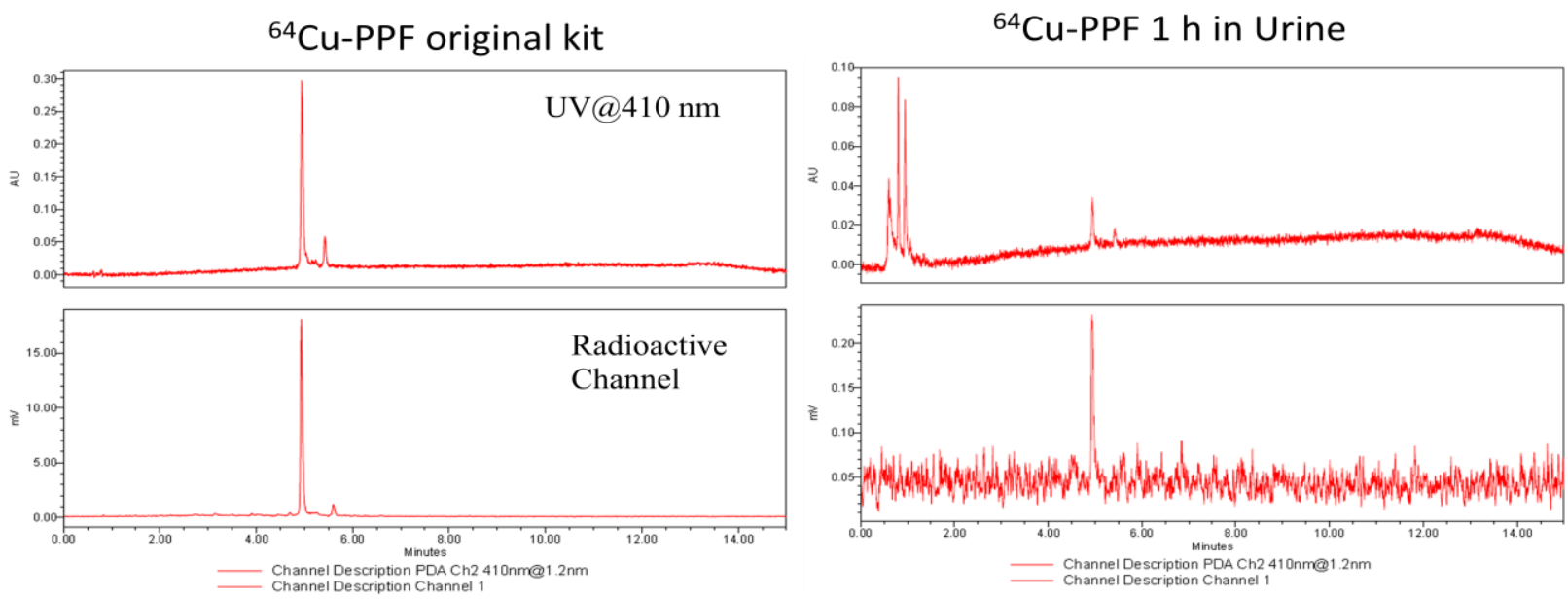

Figure 4. The metabolic stability of ${ }^{64} \mathrm{Cu}-\mathrm{PPF}$ in urine was measured by radio-UPLC with UV $410 \mathrm{~nm}$ channel and radioactivity channel at I h post injection.
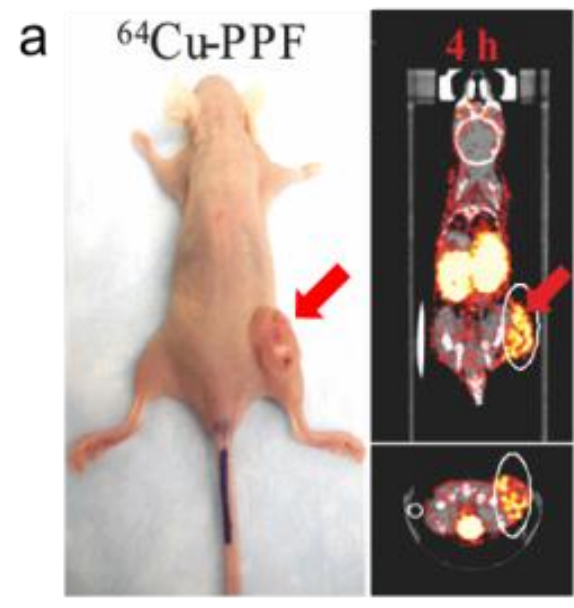

C


b

d

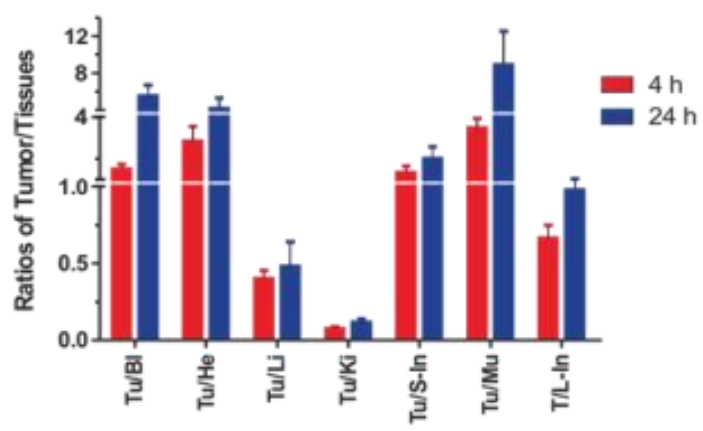

Figure 5. MicroPET/CT imaging and biodistribution. a) Representative MicroPET/CT images (coronal images (top) and single transverse slices passing through the tumors (bottom)) of KB tumor-bearing mice $(n=3)$ at $4,24 \mathrm{~h}$ after intravenous injection of ${ }^{64} \mathrm{Cu}-\mathrm{PPF}$. b) Images, including coronal images (top) and single transverse slices passing through the tumors (bottom), obtained with pre-injection $(0.5 \mathrm{~h}$ earlier) of 500 -fold excess folic acid for blockade $(n=1)$. c) Tissue uptake of ${ }^{64} \mathrm{Cu}-\mathrm{PPF}$ in selected organs at $4 \mathrm{~h}$ (red bars) and $24 \mathrm{~h}$ (blue bars) after intravenous injection. d) Ratios of tumor-to-selected organs in mice administered with ${ }^{64} \mathrm{Cu}-\mathrm{PPF}$ at $4 \mathrm{~h}$ (red bars) and $24 \mathrm{~h}$ (blue bars) post injection. Data are presented as means \pm I SD $(n=3)$. 
However, the tumor-to-muscle ratio of ${ }^{64} \mathrm{Cu}-\mathrm{PPF}$ was $3.47 \pm 0.47$ at $4 \mathrm{~h}$ and $8.88 \pm 3.60$ at $24 \mathrm{~h}$ post injection (Figure $5 \mathrm{~d}$ ), demonstrating the fast clearance of ${ }^{64} \mathrm{Cu}-\mathrm{PPF}$ in non-target tissues while ${ }^{64} \mathrm{Cu}-\mathrm{PPF}$ is retained within the tumor. Previous studies evaluating the biodistribution of ${ }^{64} \mathrm{Cu}$-labelled hematoporphyrin derivatives demonstrated no higher than a $1.07 \pm 0.25$ $\%$ ID/g [14]. Blocking biodistribution studies further demonstrated the FR-specific uptake (Supplementary Material: Figure S2). Additional experiments with another FR-positive tumors confirmed these current findings (MicroPET imaging results of MT-1, a human breast cancer model, are shown in Supplementary Material: Figure S3).

\section{Conclusions}

Through the present study, we hope to revitalize this field of radio-metalloporphyrin, based on the demonstration of ${ }^{64} \mathrm{Cu}-\mathrm{PPF}$ as a targeted PET imaging probe for FR-positive tumors. We have shown the ease and efficient radiolabeling of PPF with ${ }^{64} \mathrm{Cu}$, while retaining its favorable biodistribution, pharmacokinetics and selective tumor uptake, characteristics that were first demonstrated optically. Clearly, the $12.7 \mathrm{~h}$ half-life of ${ }^{64} \mathrm{Cu}$ is compatible with the pharmacokinetics of PPF, providing adequate time for both the radiolabeling chemistry and accumulation of ${ }^{64} \mathrm{Cu}$-PPF at tumor sites. Lastly, we report the first stable chelation of ${ }^{64} \mathrm{Cu}$ with a chlorophyll moiety, pyro. Not only is ${ }^{64} \mathrm{Cu}-\mathrm{PPF}$ a promising diagnostic tool for FR-positive tumors, the use of ${ }^{64} \mathrm{Cu}-\mathrm{PPF}$ may be employed for prediction and quantitative measurements of photosensitizer accumulation in tumors to aid in treatment planning and monitoring of PDT treatments. Radiolabeling PPF also provides a more accurate and quantitative measurement of the probe's in vivo biodistribution, due to the difficulty of absolute quantification of fluorescence in vivo. The ease and stable chelation of ${ }^{64} \mathrm{Cu}$ warrants further investigation of other radioisotopes more suitable for clinical PET imaging studies that may also form highly stable metalloporphyrin complexes such as ${ }^{60} \mathrm{Cu}$ and ${ }^{62} \mathrm{Cu}$ [30]. With the multifunctional properties of porphyrins and the efficient and stable incorporation of ${ }^{64} \mathrm{Cu}$, this approach of first developing a porphyrin-based optical theranostic probe with excellent in vivo tumor targeting characteristics and then switching it a targeted nuclear imaging probe through chelation of a radioisotope can be translated to any targeted porphyrin-based agent.

\section{Acknowledgements}

Financial support for this work was provided by the Ontario Institute for Cancer Research, the Canadian Institute of Health Research, the DOD BCRP Predoc Award W81XWH-10-1-0115, the Natural Sciences and Engineering Research Council of Canada, the Canadian Foundation of Innovation, China "973" project (2011CB707703), NSFC project (30930030), and the Joey and Toby Tanenbaum/Brazilian Ball Chair in Prostate Cancer Research. We thank Dr. Tab Siqiddi for his help with the radio-UPLC technique.

\section{Supplementary Material}

In vivo optical imaging study using the unlabeled PPF, in vivo folic acid blocking study of ${ }^{64} \mathrm{Cu}-\mathrm{PPF}$, and MicroP$\mathrm{ET} / \mathrm{CT}$ imaging and biodistribution study of ${ }^{64} \mathrm{Cu}-\mathrm{PPF}$ in a different tumor model (MT-I). http://www.thno.org/v0Ip0363s I.pdf

\section{Conflict of Interest}

The authors have declared that no conflict of interest exists.

\section{References}

1. Kadish $\mathrm{K}$, et al. The Porphyrin Handbook. Boston, USA: Academic Press; 2011.

2. Lovell JF, Jin CS, Huynh E, Jin H, Kim C, Rubinstein JL, et al. Porphysome nanovesicles generated by porphyrin bilayers for use as multimodal biophotonic contrast agents. Nat Mater. 2011; 10: 324-32.

3. Dougherty TJ, Gomer CJ, Henderson BW, Jori G, Kessel D, Korbelik M, et al. Photodynamic therapy. J Natl Cancer Inst. 1998; 90: 889-905.

4. Liu TW, Chen J, Zheng G. Peptide-based molecular beacons for cancer imaging and therapy. Amino acids. 2010; epub.

5. Ethirajan M, Chen Y, Joshi P, Pandey RK. The role of porphyrin chemistry in tumor imaging and photodynamic therapy. Chem Soc Rev. 2011; 40: 340-62.

6. Stefflova K, Chen J, Zheng G. Killer beacons for combined cancer imaging and therapy. Curr Med Chem. 2007; 14: 2110-25.

7. Lovell JF, Liu TW, Chen J, Zheng G. Activatable photosensitizers for imaging and therapy. Chem Rev. 2010; 110: 2839-57.

8. Ali H e al. Metal Complexes as Photo- and Radiosensitizers. Chem Rev. 1999; 99: 2379-450.

9. Bases R, Brodie SS, Rubenfeld S. Attempts at tumor localization using $\mathrm{Cu}$ 64-labeled copper porphyrins. Cancer. 1958; 11: 259-63.

10. Wrenn FRJr., Good ML, Handler P. The use of positron-emitting radioisotopes for the localization of brain tumors. Science. 1951; 113: 525-7.

11. Jacobson O, Weiss ID, Szajek LP, Niu G, Ma Y, Kiesewetter DO, et al. PET imaging of CXCR4 using copper-64 labeled peptide antagonist. Theranostics. 2011; 1: 251-62.

12. Zhang $Y$, Yang $Y$, Cai W. Multimodality Imaging of Integrin alpha(v)beta(3) Expression. Theranostics. 2011; 1: 135-48.

13. Firnau G, Maass D, Wilson BC, Jeeves WP. $64 \mathrm{Cu}$ labelling of hematoporphyrin derivative for non-invasive in-vivo measurements of tumour uptake. Prog Clin Biol Res. 1984; 170: 629-36.

14. Wilson BC, Firnau G, Jeeves WP, Brown KL, Burns-McCormick DM. Chromatographic analysis and tissue distribution of 
radiocopper-labelled haematoporphyrin derivatives. Laser Med Sci. 1988; 3: 71-80.

15. Soucy-Faulkner A, et al. Copper-64 labeled sulfophthalocyanines for positron emission tomography (PET) imaging in tumor-bearing rats. Journal of Porphyrins and Phthalocyanines. 2008; 12: 49-53.

16. Roberts JC, Newmyer SL, Mercer-Smith JA, Schreyer SA, Lavallee DK. Labeling antibodies with copper radionuclides using N-4-nitrobenzyl-5-(4-carboxyphenyl)-10,15,20-tris (4-sulfophenyl) porphine. Int J Rad Appl Instrum A. 1989; 40: $775-81$.

17. Stefflova K, Li H, Chen J, Zheng G. Peptide-based pharmacomodulation of a cancer-targeted optical imaging and photodynamic therapy agent. Bioconjug Chem. 2007; 18: 379-88.

18. Hambright P, Fawwaz R, Valk P, McRae J, Bearden AJ. The distribution of various water soluble radioactive metalloporphyrins in tumor bearing mice. Bioinorg Chem. 1975; 5: 87-92.

19. Gambhir SS. Molecular imaging of cancer with positron emission tomography. Nat Rev Cancer. 2002; 2: 683-93.

20. Chen $X$. Integrin Targeted Imaging and Therapy. Theranostics. 2011; 2011: 28-9.

21. Beer AJ, Kessler H, Wester HJ, Schwaiger M. PET Imaging of Integrin alphaVbeta3 Expression. Theranostics. 2011; 1: 48-57.

22. Zheng G, Chen J, Stefflova K, Jarvi M, Li H, Wilson BC. Photodynamic molecular beacon as an activatable photosensitizer based on protease-controlled singlet oxygen quenching and activation. Proc Natl Acad Sci U S A. 2007; 104: 8989-94

23. Jeong H, Huh M, Lee SJ, Koo H, Kwon IC, Jeong SY, et al. Photosensitizer-conjugated human serum albumin nanoparticles for effective photodynamic therapy. Theranostics. 2011; 1: 230-9.

24. Ferreira CL, Yapp DT, Crisp S, Sutherland BW, Ng SS, Gleave $\mathrm{M}$, et al. Comparison of bifunctional chelates for $(64) \mathrm{Cu}$ antibody imaging. Eur J Nucl Med Mol Imaging. 2010; 37: 2117-26.

25. Ferreira CL, Yapp DT, Lamsa E, Gleave M, Bensimon C, Jurek $\mathrm{P}$, et al. Evaluation of novel bifunctional chelates for the development of $\mathrm{Cu}$-64-based radiopharmaceuticals. Nucl Med Biol. 2008; 35: 875-82.

26. Wadas TJ, Wong EH, Weisman GR, Anderson CJ. Copper chelation chemistry and its role in copper radiopharmaceuticals. Curr Pharm Des. 2007; 13: 3-16.

27. Lewis J, Laforest R, Buettner T, Song S, Fujibayashi Y, Connett J, et al. Copper-64-diacetyl-bis(N4-methylthiosemicarbazone): An agent for radiotherapy. Proc Natl Acad Sci U S A. 2001; 98 : 1206-11.

28. Lewis JS, Lewis MR, Cutler PD, Srinivasan A, Schmidt MA, Schwarz SW, et al. Radiotherapy and dosimetry of 64Cu-TETA-Tyr3-octreotate in a somatostatin receptor-positive, tumor-bearing rat model. Clin Cancer Res. 1999; 5: 3608-16.

29. Anderson CJ, Jones LA, Bass LA, Sherman EL, McCarthy DW, Cutler PD, et al. Radiotherapy, toxicity and dosimetry of copper-64-TETA-octreotide in tumor-bearing rats. J Nucl Med. 1998; 39: 1944-51.

30. Williams HA, Robinson S, Julyan P, Zweit J, Hastings D. A comparison of PET imaging characteristics of various copper radioisotopes. Eur J Nucl Med Mol Imaging. 2005; 32: 1473-80. 